\title{
STUDI TERHADAP PERGAULAN LINTAS AGAMA DALAM MENINGKATKAN KEARIFAN SOSIAL MAHASISWA DI IKIP BUDI UTOMO MALANG
}

\author{
Choirul Kurniawan, Mellina Sari Tobing, Moh. Zaini \\ IKIP Budi Utomo Malang \\ Nur_zaima@yahoo.com
}

\begin{abstract}
ABSTRAK
Pergaulan sosial dalam keseharian merupakan hal yang lumrah ada dan terjadi secara natural. Namun tidak otomatis ada jaminan bahwa pergaulan tersebut tanpa melahirkan konflik, bahkan sebaliknya naturalitas yang ada berkemungkinan berpotensi menciptakan 'ruang sensitif' dari berbagai keragaman; etnis, budaya, bahkan agama. Dalam konteks pergaulan lintas agama mahasiswa, menempati posisi yang sensitif. Hal ini terletak pada 'ketabuan' mahasiswa dalam membicarakan 'persoalan-persoalan' perbedaan agama. Jika hal ini yang menjadi realitasnya maka bisa saja suatu saat nanti 'ketabuan' tersebut menjadi pusat kebuntuan, sehingga menghambat dalam proses pergaualan. Hal ini tidak saja akan menyebabkan culture of silant, namun juga dapat menyebabkan sosial conflict, sehingga mempengaruhi harmonisasi sosial lintas agama dalam lingkup pergaulan pendidikan antar mahasiswa di IKIP Budi Utomo Malang. Aktifitas yang akan dilakukan adalah menganalisis hubungan sosial lintas keagamaan mahasiswa di IKIP Budi Utomo Malang dengan tujuan menemukan pola hubungan sosial lintas agama mahasiswa, dan memberikan tawaran konsep sosial engineering pergaulan lintas agama sehingga kearifan sosial (sosial wisdom) keberagamaan di tingkat mahasiswa menjadi lebih baik. Pendekatan yang digunakan adalah pendekatan kualitatif-fenomenologis, menggunakan instrumen indept interview, dokumentasi, dan observasi/partisipan. Model analisis yang digunakan adalah model analisis Miles dan Huberman: data collection, data display, data reduction dan conclusions: drawing/verifying. Sedangkan grand theory yang digunakan adalah menggunakan teori-teori sosiologi agama.
\end{abstract}

Kata Kunci: kearifan sosial, keberagamaan, pergaulan lintas agama

\section{ABSTRACT}

Social interactions in everyday life are commonplace and occur naturally. But there is no automatic guarantee that the association without giving birth to a conflict, on the contrary, the existing naturality has the potential to create a 'sensitive space' from a variety of diversity; ethnicity, culture, even religion. In the context of student interfaith relations, occupy a sensitive position. This lies in the "taboo" of students in discussing "issues" of religious differences. If this is the reality, it could be that someday the "fortitude" will become the center of the deadlock, thus hampering the process of socializing. This will not only lead to culture of silence, but can also lead to social conflict, thus affecting the social harmonization across religions within the scope of education relations among students at the IKIP Budi Utomo Malang. Activities that will be carried out are analyzing cross-religious social relations of students at IKIP Budi Utomo Malang with the aim of finding patterns of interfaith social relations among students, and offering social concepts of engineering interfaith relations so that religious social (social) wisdom at the student level becomes better. The approach used is a qualitative-phenomenological approach, using indept interview, documentation, and observation / participant instruments. The analysis model used is the Miles and Huberman analysis model: data collection, data display, data reduction and conclusions: drawing / verifying. While the grand theory used is to use sociological theories of religion.

Keywords: social wisdom, diversity, interfaith relations 


\section{PENDAHULUAN}

Masalah pergaulan antar person melalui lingkup sosial masyarakat baik masyarakat dalam arti luas atau dalam arti sempit (spesifik; komunitas tertentu) merupakan hal yang lumrah ada dan hal tersebut terjadi secara natural. Namun demikian hal ini tidak secara otomatis adanya jaminan bahwa pergaulan tersebut tanpa melahirkan konflik, bahkan sebaliknya naturalitas yang ada berkemungkinan berpotensi menciptakan 'ruang sensitif' dari berbagai keragaman; etnis, budaya, bahkan agama.

Di dalam teori tipologi adaptasi, sebagaimana dikatakan Robert $\mathrm{K}$. Merton tentang penyimpangan melalui struktural sosial, dikatakan bahwa struktur sosial bukan hanya menghasilkan perilaku yang konformis (sesuai dengan norma) melainkan juga menghasilkan perilaku yang menyimpang. Struktur sosial dapat menghasilkan pelanggaran terhadap aturan sosial dan juga menghasilkan anomie yaitu pudarnya kaidah. Melihat dari teori ini dapat tergambar bahwa kondusifnya sebuah relasi sosial dalam sebuah komunitas tertentu tidak sama sekali memberikan jaminan bahwa ketenangan telah terkonstruk dengan baik, melainkan sebaliknya bisa menjadi titik kerawanan yang membahayakan terhadap sistem sosial yang ada.

Institut Keguruan IImu Pendidikan (IKIP) Budi Utomo
Malang, merupakan perguruan tinggi yang sebagian besar peserta didiknya berasal dari Nusa Tenggara Timur, khususnya Flores, Sumba, Timor Barat, dan Alor (Flobamora). Sedangkan sebagian kecil peserta didik lainnya berasal dari Kalimantan Barat, Kalimantan Timur, Kalimantan Utara, Jawa Timur, Jawa Barat, dan beberapa daerah lainnya dalam jumlah yang sangat kecil. Dari jumlah mayoritas $80 \%$ yang didominasi oleh Mahasiswa asal Flobamora, dengan serta merta didominasi pula oleh jumlah penganut agama Katolik dan Kristen Protestan. Sedangkan agama mahasiswa yang berasal dari daerah lainnya adalah Islam.

Dari deskripsi di atas, menggambarkan bahwa keragaman asal daerah Mahasiswa merupakan sebuah potensi plural yang berkumpul menjadi sebuah komunitas baru di dunia pendidikan. Antara satu dengan yang lain baik secara langsung atau tidak langsung saling mengenalkan diri, membaur dan bergaul, seakan-akan tidak lagi mengedepankan latarbelakang etnis, kultur, bahkan Agama yang dianut.

Perbedaan agama merupakan realitas mutlaq yang tidak dapat dipungkiri keberadaannya. Keberadaanya merupakan bagian dari hazanah ummat di semua level kehidupan manusia, -khususnya di 'komunitas elit' pergaulan mahasiswa. Perbedaan paham keyakinan tersebut tentu tidak dapat 'dikawinkan' antara agama satu 
dengan yang lain (singkritisme).

Tetapi sebaliknya, didialogkan dengan prinsip saling menghormati dan menghargai sebagai kontribusi dan perluasan pemahaman keberagamaan, sehingga mampu melahirkan rasa saling mengerti, saling menghargai dan tidak menjadi penghambat bagi keberlangsungan pergaulan lintas agama dalam lingkup pendidikan di IKIP Budi Utomo Malang.

Myers mengatakan bahwa keyakinan agama dan partisipasi sosial merupakan indikator untuk membangun religiositas suatu masyarakat. Keyakinan ini menghasilkan kesimpulan umum yang menyebutkan bahwa ada hubungan antara pemahaman agama dengan partisipasi kehidupanberagama. Hubungan antar pemahaman agama inilah yang tentu dapat dijadikan sebagai benang merah dalam mengurai masalah stagnasi sosio-dialogis keberagamaan, sehingga diharapkan akan terbentuk iklim sosio-dialogis keberagamaan kondusif dan respon positif. Namun demikian tentu dibutuhkan pembuktian-pembuktian ilmiah dalam kontek pergaulan lintas agama mahasiswa IKIP Budi Utomo. Oleh karena itu judul yang diangkat dalam penelitian ini, yakni Studi Terhadap Pergaulan Lintas Agama dalam Meningkatkan Kearifan Sosial Mahasiswa di IKIP Budi Utomo Malang.

\section{METODE PENELITIAN}

\section{Pendekatan dan jenis penelitian}

Dalam penelitian ini, pendekatan yang akan digunakan adalah pendekatan kualitatif dengan desain fenomenologis. Hal ini berkaitan langsung dengan gejalagejala yang muncul dalam pergaulan lintas agama mahasiswa di lingkungan kampus, sehingga peneliti dapat memahami makna peristiwa serta interaksi yang terjadi dalam situasi tertentu.

Selanjutnya peneliti berupaya mengkaji, menginterpretasikan dan menganalisis fenomena yang ada, membuat kerangka konsep pergaulan lintas agama untuk mempertahankan dan meningkatkan kearifan sosial lintas agama mahasiswa di IKIP Budi Utomo Malang.

\section{Sumber dan Jenis Data}

Sumber data utama (data primer) dalam penelitian ini, diantaranya: 1. kata-kata lisan melalui data hasil interview, 2. tulisan melalui data dokumentasi, 3. tindakan melalui data hasil observasi. Sedangkan data sekunder dalam penelitian ini, diantaranya; UUD 1945 dan SKB Kerukunan Beragama No. 9 dan No. 8 tahun 2006 tentang Pedoman Pelaksanaan Tugas Kepala Daerah/Wakil Kepala Daerah dalam Pemeliharaan Kerukunan Umat Beragama, Pemberdayaan Forum Kerukunan Umat Beragama dan Pendirian Rumah Ibadah. Selain data sekunder tersebut, juga didukung 
dengan referensi penguat lainnya, yakni jurnal-jurnal terkait, media cetak/on line dan arsip-arsip resmi lainnya.

\section{Instrumen Pengumpulan Data}

Pengambilan data dalam penelitian ini dilakukan secara purpossive, yang didasarkan pada pilihan peneliti tentang aspek dan subjek yang dijadikan fokus pada penelitian. Kedudukan peneliti dalam penelitian ini adalah sebagai 'instrument', yakni melakukan perencanaan, pengumpul data, analis, penafsir data dan pada akhirnya melakukan pelaporan hasil penelitian. Sedangkan instrumen yang digunakan, di antaranya dokumentasi, interview dan observasi.

Adapun data dokumen yang dibutuhkan dalam penelitian ini adalah 1. data program umum ataupun spesifik terkait dengan hubungan sosial lintas agama mahasiswa di IKIP Budi Utomo, 2. data detil prosentase penganut agama (muslim-non muslim), Mahasiswa, 3. data-data tentang berbagai kebijakan instruktif bersifat struktural terkait dengan hubungan lintas agama mahasiswa, dan dokumen terkait lainnya. Data-data tersebut diperkuat dengan data hasil in-depth interviewmahasiswa lintas agama, dosen dan pejabat terkait (bagian Kemahasiswaan), pimpinan FKUB kota Malang, dan pakar sosiologi agama. Sedangkan data penguat lainnya adalah data hasil observasi berdasarkan hasil pengamatan peneliti di kampus terkait dengan hubungan sosial lintas agama mahasiswa, dimulai sejak awal jam perkuliahan, jam masuk kelas (mulai proses pembelajaran, di kelas/di luar kelas), jam-jam istirahat, sampai dengan proses akhir perkuliahan di kampus (jam-jam pulang).

\section{Analisis Data}

Analisa data merupakan proses mencari dan menyusun secara sistematis data yang diperoleh dari hasil wawancara, catatan lapangan dan bahan-bahan lain sehingga dapat dengan mudah dipahami dan temuannya dapat diinformasikan secara ilmiah.

Sedangkan data yang diperoleh melalui in-depth interview, observasi, dan dokumentasi dianalisis menggunakan metode content analysis dengan model interaktif (interactive model). Dalam hal ini, meliputi 4 (empat) tahapan, yakni: 1) pengumpulan data (data collection), 2) penyederhanaan atau (data reduction), 3) penyajian data (data display), 4) kesimpulan-kesimpulan: penarikan verifikasi (conclusions: drawing/verifying).

\section{HASIL PENELITIAN}

Penelitian secara umum adalah proses pengamatan dan pencatatan secara sistematis mengenai gejalagejala yang diteliti. Dapat dikatakan 
juga bahwa observasi adalah salah satu metode pengumpulan data dengan mengamati atau meninjau secara cermat dan langsung di lokasi penelitian atau lapangan untuk mengetahui secara langsung kondisi yang terjadi atau untuk membuktikan kebenaran dari sebuah desain penelitian.

Kegiatan observasi ini menjadi salah satu dari teknik pengumpulan data apabila sesuai dengan tujuan penelitian, yang direncanakan dan dicatat secara sistematis, serta dapat dikontrol keandalan (reliabilitas) dan kesahihannya (validitasnya).

Dalam penelitian berjudul "Studi Terhadap Pergaulan Lintas Agama dalam Meningkatkan Kearifan Sosial Mahasiswa di IKIP Budi Utomo Malang" penulis berusaha mengumpulkan data dari internal kampus dan dikorelasikan dengan program FKUB Kota Malang tentang Tri Kerukunan. Tri kerukunan umat beragama bertujuan agar masyarakat Indonesia dapat hayati dalam kebersamaan, sekali pun banyak perbedaan. Konsep ini dirumuskan dengan teliti dan bijak agar tak terjadi pengekangan atau pengurangan hak-hak manusia dalam menjalankan kewajiban dari ajaranajaran agama yang diyakininya. Tri kerukunan ini meliputi tiga kerukunan, yaitu: Kerukunan intern umat beragama, Kerukunan antar umat beragama, dan Kerukunan antara umat beragama dan pemerintah.
Sedangkan dalam internal kampus IKIP Budi Utomo Malang sendiri sebagai kampus multikultural dalam mewujudkan itu dikemas dalam sebuah kegiatan wajib diikuti khususnya mahasiswa baru dengan nama PAKSOPMA (Program Pengembangan Sosial Mahasiswa). Menurut bidang kemahasiswaan Bapak Herman Kusdianto, M.Pd, bahwa kegiatan Pasokma diselenggarakan setahun dua kali, dengan sasaran pencapaian adalah mahasiswa mampu berbaur dan bersosialisasi dengan masyarakat. Adapun kegiatan ini pelatihan yang diselenggarakan internal kampus dan sebagai pemateri diambilkan dari dosen-dosen yang memiliki kompetensi dengan kegiatan tersebut.

$$
\text { Kegiatan }
$$

Paksopma

dilaksanakan secara rutin khususnya mahasiswa baru dengan lama kegiatan 3 hari, dan kegiatan ini merupakan prasyrat yudisium kelulusan mahasiswa. Materi pokok kegiatan ini mencakup penanaman diri tentang 1 . menghargai sesama 2. menghargai lingkungan, dengan dikemas dengan kegiatan yang menyenangkan seperti outbond, ceramah, dan kunjungan. Penyampaiaan dengan metode yang menyenangkan diharapkan mahasiswa yang mengikuti kegiatan ini secara tidak langsung akan mendapatkan materi dengan nilainilai kemanusiaan khusunya keberagaman agama, suku, dan ras 
mengingat kampus multikultural.

Dalam hasil wawancara dengan

Bapak Herman Kusdianto, M.Pd

Bidang Kemahasiswaan, bahwa target utama dalam program penanaman Kampus Multikultural adalah menumbuhkan perasaan senang dan nyaman dalam diri setiap mahasiswa.

Paksopma pertama kali dilaksanakan 29 mei 2010, mengingat kegiatan ini dimasukkan dalam mata kuliah kebudiutamaan dengan beban 2 sks dilaksanakan setiap semester ganjil (semester 3). Secara teknis kegiatan ini dilaksanakan dengan bekerjasama dengan BEM Ikip Budi Utomo Malang, sebab keterbatasan pegawai Bidang Kemahasiswaan sebagai pendampingan dalam kegiatan ini.

a. Data Interview

Pengumpulan data, dapat dimaknai juga sebagai kegiatan peneliti dalam upaya mengumpulkan sejumlah data lapangan yang diperlukan untuk menjawab pertanyaan penelitian (untuk penelitian kualitatif), atau menguji hipotesis (untuk penelitian kuantitatif).

Merujuk pada pengertian di atas, betapa pentingnya pengumpulan data dalam proses penelitian. Tanpa data lapangan, proses analisis data dan kesimpulan hasil penelitian, tidak dapat dilaksanakan. Ada perbedaan yang cukup mendasar mengenai pengumpulan data dalam penelitian kuantitatif dan kualitatif. Oleh karena itu, membahas pengertian pengumpulan data tidak hanya pada pemahaman pengertiannya saja, akan tetapi perlu dipahami juga, bagaimana pengumpulan data dalam penelitian kuantitatif dan kualitatif. Pengumpulan data dalam penelitian kuantitatif dalam pelaksanaannya tidak mesti harus langsung oleh peneliti, akan tetapi dapat dilakukan melalui pihak lain yang dipandang mampu atau kompeten dalam melaksanakan pengumpulan data. Atas dasar tersebut, maka instrumen penelitian yang akan digunakan, harus memenuhi syarat-syarat instrumen penelitian.

Dalam hasil wawancara yang dilakukan peneliti sebagaimana teori Gay dan Diehl (1992) ini mengasumsikan bahwa semakin banyak sampel yang diambil maka akan semakin representatif dan hasilnya dapat digenelisir. Namun ukuran sampel yang diterima akan sangat bergantung pada jenis penelitiannya.

1. Jika penelitiannya bersifat deskriptif, maka sampel minimunya adalah $10 \%$ dari populasi

2. Jika penelitianya korelasional, sampel minimunya adalah 30 subjek

3. Apabila penelitian kausal perbandingan, sampelnya sebanyak 30 subjek per group 
4. Apabila

penelitian

eksperimental, sampel minimumnya adalah 15 subjek per group

Karena dalam penelitian ini bersifat deskriptif maka peneliti mengambil 100 sample mahasiswa dari berbagai unsur agama, suku, dan ras mengingat mahasiswa IKIP Budi Utomo angkatan 2016/2017 berjumlah 1000 mahasiswa.

Sebagaimana luaran penelitian ini mngangkat tema hubungan antar mahasiswa lintas agama dan dampak ke sosial masyarakat, maka dapat disimpulkan bahwa hasil wawancara dengan mahasiswa dari program kegiatan Paksopma sebagai berikut :

1. Ada perubahan sikap dari setiap mahasiswa untuk bisa menghormati dan menghargai perbedaan agama, suku, dan ras antar mahasiswa IKIP Budi Utomo Malang. Selain itu juga menumbuhkan rasa kasih dan sayang antar mahasiswa dalam bersosialisasi dengan antar mahasiswa, sehingga resiko munculnya gesekan dan konflik bisa diminimalisir lebih-lebih dihapuskan.

2. Ada perubahan sikap dari cultur yang dibawa setiap mahasiswa dimana mereka tinggal, berubah menjadi jati diri yang bisa membuka diri dan mampu bersosialisasi, bergaul, serta adaptasi dengan lingkungan

kampus maupun dengan

masyarakat disekitar kampus.

\section{PEMBAHASAN}

Pola pergaualan lintas agama mahasiswa di IKIP Budi Utomo Malang berdasarkan hasil paparan data dokumentasi, observasi dan interview, maka dapat dianalisa, adalah sebagai berikut:

1. Bahwa untuk mewujudkan perubahan sikap dari setiap mahasiswa untuk bisa menghormati dan menghargai perbedaan agama, suku, dan ras antar mahasiswa IKIP Budi Utomo Malang perlu dikakukan secara berkala dan terstruktur. Selain itu juga menumbuhkan rasa kasih dan sayang antar mahasiswa dalam bersosialisasi dengan antar mahasiswa, sehingga resiko munculnya gesekan dan konflik bisa diminimalisir lebih-lebih dihapuskan, jika ada kerjasama yang kuat dari institusi kampus dengan berbagai elemen kampus.

2. Bahwa untuk mewujudkan perubahan sikap dari cultur yang dibawa setiap mahasiswa dimana mereka tinggal, berubah menjadi jati diri yang bisa membuka diri dan mampu bersosialisasi, bergaul, serta adaptasi dengan lingkungan kampus maupun dengan masyarakat disekitar kampus butuh pengenalan dan pembekalan secara masif dari pihak kampus agar bisa tercapai. 
3. Meningkatkan kearifan sosial dalam pergaulan lintas agama mahasiswa di IKIP Budi Utomo Malang

\section{SIMPULAN}

Berdasarkan hasil paparan data dokumentasi, observasi dan interview, maka dapat dianalisa, adalah sebagai berikut:

1. Perlu ada hubungan kerjasama yang baik antara pihak kampus dengan masyarakat maupun stakeholder, dalam hal ini dilakukan Bidang Humas (Hubungan masyarakat)

2. Evaluasi harus dilakukan secara berkala bagi lingkungan kampus untuk memantau sikap dan perilaku mahasiswa sebagai objek kajian penelitian ini, sehingga kearifan lokal sosial dalam pergaulan lintas agama pada mahasiswa IKIP Budi Utomo Malang dapat terwujud.

\section{DAFTAR PUSTAKA}

Depag RI, 1997. Bingkai Teologi Kerukunan Hidup Umat Beragama Di Indonesia, (Jakarta; Badan Penelitian dan Pengembangan Agama Proyek Peningkatan Kerukunan Umat Beragama di Indonesia)

Depag RI, 1997. Bingkai Teologi Kerukunan HidupUmat Beragama Di Indonesia, (Jakarta; Badan Penelitian dan Pengembangan Agama Proyek Peningkatan Kerukunan Umat Beragama di Indonesia)
Elisa.ugm.ac.id/community/show/sos iologiagamaolehandreassoeros o/topik:Sosiolog memahami Agama. Diakses tanggal. $21 \mathrm{Mei}$ 2016

http://priyonisme.blogspot.co.id/201 3/08/teori-tindakanrasionalitas-max-weber.html, diaksestgl. 14 Maret 2017, pukul: 14.45

Ishomuddin, 2002. Pengantar Sosiologi Agama, Jakarta: PT. Ghalia Indonesia-UMM Press

Kahmad, Dadang, 2000. Sosiologi Agama. Bandung: PT. RemajaRosdakarya

Lubis, Ridwan. 2005. Cetak Biru Peran Agama, (Jakarta, Puslitbang)

Lubis, Ridwan. 2015. Sosiologi agama; memahami perkembangan agama dalam interaksi sosial. Jakarta: Prenada Media Group

Majid, Nurcholis. 1992. Islam, Doktrin dan Peradaban, Jakarta: Paramadina

Manshur, Fadlil Munawwar. 2003. Sociology of Religion, edited by Michele Dillon University of New Hampshire, Cambridge University Press

Moleong, Lexy J. 2006. Metodologi Penelitian Kualitatif. Bandung: Remaja Rosda Karya

Narwoko, J. Dwi dan Suyanto, Bagong. 2006. Perkembangan dan peran sosiologi, dalam J. Dwi Narwoko Bagong Suyanto (ed), sosiologi teks pengantar dan terapan. Jakarata: Kencana Prenada Media Group 
Nasution. 2006. Metode Research

(Penelitian Ilmiah). Jakarta:

Bumi Aksara

R.C, Bogdan., dan Biklen, S.K. 1998.

Qualitative Research for Education. Boston: Allyn and Bacon, Miles dan Huberman. 1987. Analisis Data Kualitatif. Terjemahan. Jakarta: Yayasan Penerbitan Universitas Indonesia

Ritzer, George and Douglas J. Goodman. 2008. Teori Sosiologi dari Sosiologi Klasik sampai Perkembangan Muthakir Teori Sosial Post Modern. Yogyakarta: Kreasi Wacana.

Said Agil Munawar, 2005. Fikih Hubungan Antar Umat Beragama (Jakarta, Ciputat Press)

Suharsimi, Arikunto. 2002. Metodologi Penelitian. Penerbit PT. Rineka Cipta. Jakarta

Sunuyeko, Nurcholis. 2016. (ringkasan Desertasi) Interaksi sosial mahasiswa rantau; kajian adaptasi dan akulturasi mahasiswa asal Flobamora di sebuah perguruan tinggi swasta multi etnik kota Malang. Ujian terbuka di Program Studi Doktor Ilmu Sosial, Program Pascasarjana Universitas Merdeka Malang,

Syaukani, Imam. 2008. Kompilasi Kebijakan Dan Peraturan Perundang-Undangan

Kerukunan Umat Beragama (Jakarta, Puslitbang)

Thoha, Malik, Anis, 2005. Tren Pluralisme Agama, Tinjauan kritis, Jakarta, Perspektif, cet. I 